\title{
Analysis on the Psychological Causes of Current Buzzwords on College Campus in China
}

\author{
Zhu Shuping \\ School of Elementary Education at Zaozhuang University
}

Keywords: Buzzwords on College Campus; Psychological Incentive; "Like Attracts Like" Mentality; Curiosity and "Seeking Difference" Mentality; Imitation Mentality

\begin{abstract}
Buzzwords on college campus are an important part of the on-campus cultural environment, and its production, popularity and changes objectively reflect the ideological trends and mentality trends of college students in life. This paper makes a concise analysis of the psychological incentives of buzzwords on college campus from three aspects in order to provide useful materials for the young students to lead the correct psychological counseling and growth.
\end{abstract}

\section{Introduction to Popular Words on College Campus}

Buzzwords are a form of language that is widely prevalent in the oral communication of certain communities and even members of society in a particular area. It reflects the changes in social life and conveys the values and dynamics of people's values and social attitudes. Almost all changes in social life can be characterized by language, only because the different expressions of the boundaries and groups are different. Because of the inherent presupposition of language, it can vividly reflect the state of life. As Mr. Chen Yuan pointed out in "Social Linguistics", new things have appeared in social life, and this new thing has to do everything in the language. The people in the social group who are active in thinking, have strong information reception ability, and are easily interfered by the outside world are young college students living in special circumstances. They are undoubtedly the mainstream of spreading and using buzzwords. For example, Xia Zhonghua said that the creation and use of buzzwords should belong to the younger generation. They have more breadth and singularity in creating imagination than middle-aged and older people. The campus is the most intensive place for young people. The speciality of interpersonal relationship and the way of life learning provide good conditions for the generation and dissemination of campus buzzwords. Some distinctive campus languages also reflect the characteristics of campus culture and the unique characteristics, mental characteristics, values, ways of thinking, etc. of young students. Campus buzzwords follow the law of language development and are a language variant. The famous linguist Richard Hudson believes that linguistic variants are a form of linguistic expression commonly used by people with the same social characteristics in the same social environment. Social dialects are languages that are often used by different social groups due to differences in people's status, occupation, and educational level. Campus buzzwords are created and disseminated by the majority of young college students. They are characterized by knowledge, humor and forward-looking. Moreover, because of the regional nature of campus buzzwords, this makes it impossible for people outside the region to understand and form a distinctive campus term. The formation and dissemination of campus buzzwords is the result of a combination of factors. This paper intends to analyze its incentives from a psychological perspective.

\section{Psychological Incentive for Popular Words on College Campus}

The university campus is a miniature organic society and a springboard for young students to enter the outside world. The energetic young college students live a colorful life in the school, making them more relaxed and free-spirited than the people in the society. The interpersonal communication on campus is relatively pure and transparent. Most of them are full of endless illusions about the future of life. They circulate in two very different environments, the external 
social environment and the campus life and study, thus forming their specific campus living and learning habits. At the same time, they also have a certain rationality, constantly thinking about it, constantly chasing their own dreams, hoping that they can show their unique side in the contemporary social stage, release themselves and publicize their individuality. In addition, they keep accumulating knowledge and experience. At the same time, compared with other social environments, the quieter and independent university campus environment enables university students to generate and use the language system unique to their group, campus buzzwords. Campus buzzwords are a language phenomenon that best expresses the psychological characteristics of college students and the most representative of the daily life of college students. Behind the formation, popularity and evolution of campus buzzwords, there are many psychological factors. These psychological reasons are also complex and diverse, and they can be roughly divided into four categories:

\section{"Like Attracts Like" Mentality}

In today's era, the division of labor is becoming more and more detailed, which inevitably leads to the infiltration of all aspects of social life into all aspects of the social and economic system, and people's role in social life is increasingly diversified and complicated. The social reality of materialism and weak flesh and blood makes people feel lonely and embarrassed at any time during this period. People feel small and insignificant in modern cities. This kind of social psychology is generally prevalent, and it is inevitable to enter the university campus with the strongest information reception ability. Because the university campus is not a pure land after all, it will inevitably be affected by the social environment. Contemporary college students are sensitive and self-respecting. They have great self-confidence and can't withstand any setbacks. They are both proud and arrogant. They believe that the future is bright, and they are confused for future life. Because they are unable to position themselves and their ambivalence in their future life, they hope that others can identify and understand themselves, and that their unique personality will not be changed. However, because each person's scope of communication has certain limitations, they cannot allow everyone to understand and agree with their thoughts. Things alike sare grouped together, so they look for people who are similar to themselves. This is the fundamental factor in the accumulation of campus buzzwords. This kind of psychology determines that college students have a clear positioning and recognition of their role. Therefore, in the large environmental group of campus buzzwords, there are some small environmental groups of buzzwords. These small environmental groups have their own buzzwords. In this small environment, they use these words that are theirs to communicate, often only they I can understand it and feel very tacit. But for people outside of their small environment, it will be difficult to understand. For example: "Irrigation" (dissipate some derogatory posts or comments on the Internet), "throw bricks" (with posts in the post bar), "I will hold you, uncle" (online comments, just give you another name), "beat the bricks" (publishing comments on the Internet to criticize some posts), "diving" (people who don't talk for a long time in the group), "Lou pig" (referring to the landlord, the first person to post), "Let's go, Pipi shrimp" (online game language, from online games), "newbie" (referring to the game's poor newcomers, now also refers to people who do not understand), "purified water" (refers to meaningless contents online), "you city people is good at seeking fun" (a shorthand for people in your city to play), "CU" (short for English goodbye), "I want to see the big world", "sprayer" (referring to on the Internet, people are willing to use language to attack others as fun.) "Take me, old driver" and "prehistoric power" (Fu Yuanhui said in an interview at the Olympics: "I have used prehistoric power" and became popular) and many more. Most of these campus buzzwords are from the Internet. If you don't go online often and don't play online games, then you can't be considered a qualified netizen. Therefore, for these network campus buzzwords, no matter what you think or guess, you don't necessarily understand what this language represents.

\section{Curiosity and "Seeking Difference" Mentality}


"Like Attracts Like" mentality is a kind of social demand. It makes the innovative buzzwords have the same attributes. This is a kind of public psychology, and the curiosity and "seeking difference" mentality more reflects the personality of college students. For today's college students, pursuing fashion and pursuing individuality can fully demonstrate their talents in this language circle, in order to show their unique charm. At the same time, this is also an inevitable phenomenon that college students use to prove their worth and reflect their feelings in the small language circle of the school. For example, when they are in a bad mood, very unhappy, and very sad, they don't say "I am sad" or "I am in blue", but they say "I want to go dying", "stay away from me", and "my heart is crashing". When they feel very tired, they say "I am tired like a dog". When they see others showing love to each other, they will say "I am fed with dog food" or "the dog food tastes good". When they fail in exams, they will say "I lose". When they continue to take the exam as a civil servant, apply for a job at a public institution or graduate studies after failing, they are called to be "fighting again". When it comes to family, they say "F-A-M-I-L-I". Among these campus buzzwords, we can understand the psychology of college students pursuing individuality and wanting to be different. It is this mentality of seeking differences that makes campus buzzwords give people a feeling of bright eyes. At the same time, the renewal and creation of modern Chinese language is also inseparable from these highly creative campus buzzwords to continuously enrich and enrich, bringing fresh blood and vitality to modern Chinese.

\section{Imitation Mentality}

Sociolinguists believe that language is a dynamic system, and that social change provides important conditions for language change. Imitation is a common phenomenon. In speech life, when people find that someone's words are very attractive to them, they tend to accept the influence because they like the speech. Contemporary college students are more individual, advocate different, and pursue fashion. However, under the influence of current social culture, especially the influence of "Korean Wave" and "Japanese Wave", college students will be assimilated by these cultures without knowing it, and then they will be unconsciously in daily life. It is expressed in the behavioral words, especially the imitation of the language movements of the movie stars that they love and admire. This is a typical imitation mentality. Just like the current popularity of Korean dramas and the great move of South Korea's "Ouba" into China's development and the release of Hollywood blockbusters "Speed and Passion 8" and "Resident Evil 6". In the university campus, you will often hear "national husband Song Zhongii", "Hollywood loyalty fans", "Korean culture lovers", "Narvto Wave" and so on. These vivid images reflect the psychology of college students, which makes female college students directly become "anthomaniac" and "fanboy". Buzzwords such as "Wow", "How Handsome", "Beer and Fried Chicken", "Axi Bar" can be heard everywhere on campus.

\section{Conformity Mentality}

Since they are buzzwords, they are inseparable from fashion and trend. Young college students are a young group with quick thinking and quick response. They have the ability to capture fashion trends much higher than ordinary people. Their language performance is also the same. Whenever there are fresh ideas and new words, they will definitely become popular among college students. Pursuit of fashion is a trend. Skillful operation of buzzwords is seen as a manifestation of maturity, ostentation, and open mind. It is also a "entry ticket" that is integrated into the university community. Only in this way can you considered by others to be "the similar kind of people". The conformity mentality is a common phenomenon in the university, which is reflected in many aspects. The conformity mentality is more prominent in the spread of campus buzzwords.

\section{Conclusion}

Language is a mirror that reflects the form of social life, while campus buzzwords vividly reflect the state of language in campus life. Campus buzzwords injects fresh blood into the Chinese family with its universal knowledge, witty interest, unique imagery and a vigorous youthful atmosphere. As an important part of campus culture, campus buzzwords have penetrated into every aspect of the campus cultural environment. There is no doubt that campus culture is closely related to popular 
culture. The two influence each other, but there is a clear distinction between mass culture and campus culture. There are differences in levels and functions. Campus buzzwords, which are part of the campus culture, are inevitably influenced by popular culture during the formation process. With the gradual maturity of China's market economy and the transformation of socialized application functions of Chinese universities, the influence of popular culture on campus culture, especially campus buzzwords, has become more and more serious. For young college students who are not fully mature in physiology and psychology, their acceptance of popular culture is irrational, with strong randomness and emotional color. Popular culture is a low-level consumer and entertainment culture. Campus culture is a higher-level culture. It has the educational function that is not possessed by popular culture. Therefore, we must carry out the necessary correct guidance for young students and reasonably absorb the popular culture separately. We can't turn a blind eye to the formation and dissemination of campus buzzwords, we must pay attention to it, strengthen research, and rationally guide it. Only by comprehensively studying the campus buzzwords can we better understand the current language habits of college students and their values and outlook on life. From the perspective of psychology, we can understand the characteristics of college students' psychological performance and development trends. Therefore, they are directed to develop in a favorable way.

\section{References}

[1] Chen Yuan. Sociolinguistics [M]. Shanghai: Xuelin Press, 1983.

[2] Xia Zhonghua. Discussion on the Basic Rationale of the Popularity of Buzzwords [J]. Language and Text Application, 2010(2).

[3] Shizhao N, Zheng W, Wangmo P, Yuan N, Peng L. Big Data Prediction of Durations for Online Collective Actions based on Peak's Timing [J]. Physica A: Statistical Mechanics and its Applications, 2018, 55: 130-139. 